\title{
Kepuasan dan Loyalitas Pasien terhadap Pelayanan di Fasilitas Kesehatan Primer: Sebuah Tinjauan Literatur
}

\author{
Muhammad Rizky Widodo' ${ }^{1}$, Diansanto Prayoga ${ }^{2}$ \\ 1,2,Departemen Administrasi dan Kebijakan Kesehatan, Fakultas Kesehatan Masyarakat, \\ Universitas Airlangga, Surabaya \\ E-mail: muhammad.rizky.widodo-2018@fkm.unair.ac.id, diansantoso_prayoga@gmail.com
}

\begin{tabular}{l}
\hline Article Info \\
\hline Article History \\
Received: 2021-12-27 \\
Revised: 2022-01-22 \\
Published: 2022-02-10
\end{tabular}

Published: 2022-02-10

Keywords: Patient Satisfaction; Patient Loyalty; Patient Trust;
Primary Healthcare.

\begin{abstract}
The complexity of customer satisfaction and loyalty as well as its large implications for the running of health services makes it important to know it, especially in primary health facilities that are in direct contact with the community and are closest to the community. Literature study was conducted to determine the factors of patient satisfaction and loyalty in primary health facilities. The method in this study was a literature study with the type of narrative review. The databases used are SCOPUS, SAGE, and Web of Science. The doctor-patient relationship is also a factor that increases satisfaction and leads to loyalty. The formation of patient loyalty to health care providers through the process of creating patient trust until loyalty arises. Meeting social needs is also an important factor so that patients have better satisfaction. Trust is a factor that mediates the formation of loyalty after patient satisfaction appears. Personalized service with a preventive approach is an innovative form of service that can increase patient satisfaction and loyalty to doctors. Primary health facilities in Indonesia can adopt existing innovations by taking into account factors related to satisfaction and loyalty. With increased satisfaction and loyalty, it is hoped that the utilization of primary health services can be high so that the coverage of health services in Indonesia is better.
\end{abstract}

\begin{tabular}{l}
\hline Artikel Info \\
\hline Sejarah Artikel \\
Diterima: $2021-12-27$ \\
Direvisi: $2022-01-22$ \\
Dipublikasi: $2022-02-10$
\end{tabular}

Kata kunci: Kepuasan Pasien; Loyalitas Pasien; Kepercayaan Pasien; Fasilitas Kesehatan; Primer.

\begin{abstract}
Abstrak
Kompleksitas kepuasan dan loyalitas pelanggan serta implikasinya yang besar terhadap berjalannya pelayanan kesehatan membuat penting untuk mengetahuinya utamanya pada fasilitas kesehatan primer yang bersentuhan langsung dengan masyarakat dan yang paling dekat dengan masyarakat. Studi literatur dilakukan untuk mengetahui faktor kepuasan dan loyalitas pasien di fasilitas kesehatan primerMetode dalam penelitian kali ini adalah studi literatur dengan jenis narrative review. Basis data yang digunakan adalah SCOPUS, SAGE, dan Web of Science. Hubungan relasional dokter-pasien juga menjadi faktor yang meningkatkan kepuasan hingga berujung pada loyalitas. Terbentuknya loyalitas pasien kepada pemberi pelayanan kesehatan melalui proses munculnya kepercayaan pasien hingga timbul loyalitas. Pemenuhan kebutuhan sosial juga menjadi faktor yang penting agar pasien memiliki kepuasan yang lebih baik. Kepercayaan menjadi faktor yang menengahi terbentuknya loyalitas setelah muncul kepuasan pasien. Pelayanan terpersonalisasi dengan pendekatan preventif menjadi inovasi bentuk pelayanan yang dapat meningkatkan kepuasan pasien dan loyalitas kepada dokter. Fasilitas kesehatan primer di Indonesia dapat mengadopsi inovasiinovasi yang ada dengan memperhatikan faktor-faktor terkait kepuasan dan loyalitas. Dengan meningkatnya kepuasan dan loyalitas, diharapkan utilisasi pelayanan kesehatan primer dapat tinggi sehingga cakupan pelayanan kesehatan di Indonesia lebih baik.
\end{abstract}

\section{PENDAHULUAN}

Kepuasan pelanggan adalah tingkat kesukaan pelanggan atas barang maupun jasa yang telah didapatkan dibandingkan dengan ekspektasi yang ada (Kotler, Roberto and Lee, 2003), sebagai bagian dari upaya untuk memperkuat institusi perawatan kesehatan primer, profesional kesehatan tingkat primer perlu memiliki pengetahuan terkini tentang tatalaksana dan manajemen yang komprehensif, dua elemen kunci dalam upaya peningkatan pelayanan medis berbagai penyakit adalah kepuasan pasien sebagai pengguna jasa dan kepatuhan terhadap standar pelayanan yang telah ditetapkan. Kepuasan pasien dengan perawatan meliputi harapan, kondisi fasilitas kesehatan, lingkungan, komunikasi dan informasi, keterlibatan dan keterlibatan, dan hubungan interpersonal (Sharew et al., 2018), implikasi kepuasan pasien adalah loyalitas pasien terhadap fasilitas kesehatan. Pasien 
yang tidak puas dengan pelayanan medis yang diterimanya bisa memutuskan untuk pindah ke rumah sakit lain yang dapat memberikan pelayanan yang lebih baik.

Pemahaman terhadap kepuasan pasien terhadap pelayanan yang diberikan memiliki implikasi yang besar, pasien yang dilaporkan memiliki pengalaman yang baik cenderung merasa puas (Eriksson and Svedlund, 2007), memiliki relasional yang lebih baik terhadap dokternya (Gonzalez et al., 2020) dan lebih patuh terhadap instruksi perawatan pasca pelayanan (Price et al., 2014), sistem ekonomi pasar mengenal inti persaingan perusahaan adalah berpusat pada pelanggan, menangkap dan menciptakan preferensi dan loyalitas pelanggan terhadap produk perusahaan. Konsep loyalitas pelanggan merupakan pusat dari pemasaran dan loyalitas pasien berakar sama dari loyalitas pelanggan di sektor bisnis (Toufaily, Ricard and Perrien, 2013), dengan penjelasan tersebut, pasien merupakan customer apabila dilihat dari sektor bisnis. Perbedaan atas loyalitas pasien ditekankan pada kondisi produk kesehatan itu sendiri, produk pelayanan kesehatan merupakan produk publik parsial yang diberikan kepada pasien yang datang ke rumah sakit untuk berobat, namun layanan medis berbeda dengan industri lain. Pasien secara pasif dirawat di rumah sakit. Secara subyektif, tidak ada keinginan untuk berkunjung lagi, dengan demikian loyalitas pelanggan industri medis sangat berbeda dengan industri lainnya.

Kompleksitas kepuasan dan loyalitas pelanggan serta implikasinya yang besar terhadap berjalannya pelayanan kesehatan membuat penting untuk mengetahuinya utamanya pada fasilitas kesehatan primer yang bersentuhan langsung dengan masyarakat dan yang paling dekat dengan masyarakat, oleh karena itu penulis akan melakukan studi literatur terkait kepuasan dan loyalitas pada organisasi fasilitas kesehatan primer.

\section{METODE PENELITIAN}

Metode dalam penelitian kali ini adalah studi literatur dengan jenis narrative review, tahapan dan petunjuk dalam melakukan narrative review mengikuti petunjuk dalam penulisan narrative review artikel jurnal yang melalui peer-review (Green, Johnson and Adams, 2006). Peneliti akan melakukan pencarian literatur secara mendalam,detail dan teliti (Nugroho, 2021), penelusuran artikel dilakukan pada 23 Januari 2021 di tiga basis data internasional yaitu SCOPUS,
SAGE, dan Web of Science, penelusuran menggunakan kata kunci berbahasa inggris yang disesuaikan dengan MeshTerms dan kata kunci terkait pertanyaan penelitian. Kueri yang digunakan adalah ("Primary Healthcare" OR "Primary care" OR "Primary healthcare") AND ("Patient satisfaction" OR "Satisfaction") AND ("Patient loyalty" OR "Loyalty"), dengan strategi pencarian tersebut, ditemukan 152 artikel.

Artikel yang didapatkan kemudian diseleksi dengan kriteria inklusi dan eksklusi, kriteria inklusi dari studi ini adalah konten artikel menjelaskan terkait faktor yang berhubungan maupun mempengaruhi kepuasan dan loyalitas pasien, termasuk original artikel, tempat organisasi pelayanan adalah fasilitas kesehatan primer, full-text dapat diakses baik dikarenakan artikel merupakan open access ataupun dilanggan oleh Universitas Airlangga. Artikel yang dieksklusikan adalah artikel yang kontennya tidak menjelaskan faktor yang mempengaruhi kepuasan dan loyalitas pasien, sisi penelitian artikel tidak pada sisi pemikiran pasien, artikel review commentary dan artikel lain yang bukan merupakan penelitian primer, full-text tidak bisa diakses, dan latar organisasi objek penelitian bukan pada fasilitas kesehatan primer. Kriteria inklusi dan eksklusi kemudian dipakai dalam menyeleksi 152 artikel yang telah didapatkan, dari 152 artikel tersebut, terpilih tujuh artikel yang akan didiskusikan dan dianalisis lebih lanjut dalam studi literatur kali ini.

\section{HASIL DAN PEMBAHASAN}

1. Deskripsi Umum Artikel

Terdapat tujuh artikel yang terpilih untuk dianalisis lebih lanjut setelah melalui proses pemilihan artikel dengan menggunakan kriteria inklusi dan eksklusi, berikut merupakan deskripsi umum dari setiap artikel:

Tabel 1. Deskripsi Umum Artikel

\begin{tabular}{clcc} 
No & $\begin{array}{c}\text { Peneliti dan Tahun } \\
\text { (Kijima et al, 2021) }\end{array}$ & $\begin{array}{c}\text { Jokang } \\
\text { Jepang }\end{array}$ & $\begin{array}{c}\text { Metode } \\
\text { Penelitian } \\
\text { Kualitatif }\end{array}$ \\
\hline 2 & $\begin{array}{l}\text { (Klemes and Solomon } \\
\text { 2015) }\end{array}$ & $\begin{array}{c}\text { Amerika } \\
\text { Serikat }\end{array}$ & Kuantitatif \\
\hline 3 & (Liu et al, 2021) & China & Kuantitatif \\
\hline 4 & $\begin{array}{l}\text { (Gray, Jones and } \\
\text { Wright, 2021) }\end{array}$ & $\begin{array}{c}\text { Amerika } \\
\text { Serikat }\end{array}$ & Kuantitatif \\
\hline 5 & (Robinson, 2016) & $\begin{array}{c}\text { Amerika } \\
\text { Serikat }\end{array}$ & Kualitatif \\
\hline 6 & (Gerard et al, 2016) & Prancis & Kualitatif \\
\hline 7 & (Nidiry et al, 2008) & $\begin{array}{c}\text { Amerika } \\
\text { Serikat }\end{array}$ & Kualitatif \\
\hline
\end{tabular}

Lokasi penelitian dari studi terpilih mayoritas berada di Amerika Serikat $(n=4)$ atau $57,14 \%$ dari total studi, kemudian disusul pada Benua Asia yaitu ada dua studi $(28,57 \%)$ 
yang dilakukan di Jepang dan China. Satu studi (14,29\%) dilakukan di Benua Eropa yaitu negara Prancis. Studi terpilih lebih banyak mengambil metode penelitian kualitatif sebanyak empat studi $(57,14 \%)$ dan sisanya memakai desain studi kuantitatif sebanyak tiga studi (42,86\%), tidak ada studi yang memakai metode penelitian campuran atau mix-method.

2. Faktor-Faktor yang Mempengaruhi Kepuasan dan Loyalitas

Terdapat tiga studi yang membahas secara khusus mengenai faktor terkait kepuasan dan loyalitas dan hal yang mempengaruhinya, penelitian tersebut adalah penelitian terkait kepuasan dan loyalitas di Jepang (Kijima et al., 2021), praktik dokter umum di fasilitas kesehatan primer pada negara Prancis (Gérard et al., 2016), kejadian penutupan fasilitas kesehatan dalam mempelajari perilaku pasien pasca penutupan faskes (Nidiry et al., 2008), dan terkait pasien dengan karakteristik tidak terpenuhinya kebutuhan sosial (Gray, Jones and Wright, 2021). Temuan dari penelitian Kijima et al (2021) menyatakan bahwa terdapat tiga faktor yang mempengaruhi kepuasan dan loyalitas, faktor yang pertama yaitu longitudinalitas pelayanan yang diberikan. Longitudinalitas pelayanan merupakan kontinuitas pelayanan yang diberikan dan diterima oleh pasien, semakin kontinyu pelayanan yang diberikan pasien makin puas dan loyal terhadap fasilitas kesehatan yang bersangkutan. Faktor yang kedua yaitu kontak pertama pasien dengan faskes, kesan saat kontak pertama saat kondisi normal (bukan darurat) mempengaruhi kepuasan pasien tetapi tidak berhubungan dengan loyalitas. Faktor yang ketiga adalah terkait sifat dari pelayanan. Praktik pelayanan yang memiliki pemahaman luar biasa atas latar belakang pasien termasuk keluarganya meningkatkan loyalitas pasien.

Penelitian dari Gérard et al (2016) menunjukkan proses dari terbentuknya loyalitas pasien yang didasarkan atas kepercayaan dan kepuasan pasien, loyalitas pasien didasarkan atas kepercayaan pasien terhadap tenaga kesehatan, hal ini muncul karena kepuasan masa lalu saat menerima pelayanan. Loyalitas pasien dibentuk secara perlahan melalui kunjungan beberapa kali di tenaga kesehatan yang sama, kepuasan yang terus timbul akan membentuk loyalitas pasien. Kunjungan pertama menjadi hal penting dalam inisiasi loyalitas, pasien memahami manfaat terkait menjadi loyal kepada fasilitas dan tenaga kesehatan. Apabila memilih pasien akan lebih senang apabila ia telah menemukan fasilitas dan tenaga kesehatan yang pasien bisa loyal kepada mereka, ketidakmampuan pasien untuk mengunjungi fasilitas dan tenaga kesehatan yang biasasnya pasien kunjungi tidak mengurangi loyalitas pasien, portabilitas dalam pelayanan kesehatan tidak mengurangi loyalitas pasien terhadap satu fasilitas dan tenaga kesehatan tertentu.

Kejadian penutupan suatu faskes primer membuat penelitian Nidiry et al (2008) memiliki pendekatan yang unik dalam menguji loyalitas pasien, dalam penelitiannya terdapat beberapa penemuan yang menarik. Penemuan yang pertama adalah Jarak menjadi faktor yang mempengaruhi kepuasan pasien. Makin jauh jarak faskes, makin rendah kepuasan pasien, perpindahan faskes yang dikunjungi pasien membuat pasien kembali mempertimbangkan fasilitas terkait medis maupun non-medis. Fasilitas modern dan baru menjadi faktor yang meningkatkan kepuasan, hubungan relasional antara pasien dengan dokter yang baik menjadi penyebab pasien loyal terhadap dokternya sehingga mengikuti dokternya pada kliniknya yang baru, apabila dilihat dari karakteristik pasien, penelitian Gray, Jones, dan Wright (2021) memberikan pandangan terhadap karakteristik pasien dengan kebutuhan sosial yang tidak terpenuhi terhadap tingkat kepuasan dan loyalitasnya. Pasien dengan kebutuhan sosial berkaitan dengan kesehatannya yang tidak terpenuhi lebih mendapatkan pengalaman yang buruk saat mendapatkan pelayanan, pasien dengan health-related social unmet needs harus lebih diperhatikan agar ketidakmerataan pelayanan kesehatan bisa lebih diatasi.

3. Peran Kepercayaan dalam Kepuasan dan Loyalitas Pasien

Peran kepercayaan dalam mencapai kepuasan dan loyalitas pasien dijelaskan dalam dua penelitian yaitu terkait dampak kepuasan terhadap loyalitas dengan mediasi kepercayaan di China (Liu et al., 2021) dan pada studi penggabungan teori pada pasien kronis (Robinson, 2016), kedua studi tersebut memasukkan kepercayaan dalam mencapai kepuasan dan loyalitas pasien di tingkat fasilitas kesehatan primer. Liu et al (2021) membangun sebuah kerangka konseptual terkait kepercayaan dalam meraih kepuasan dan 
loyalitas pasien. Penelitian tersebut mendapatkan beberapa hasil terkait pengaruh kepuasan, kepercayaan dan loyalitas pasien. Kepuasan pasien mempengaruhi tingkat kepercayaan pasien terhadap faskes, kepercayaan pasien mempengaruhi tingkat loyalitas terhadap faskes. Kepuasan pasien mempengaruhi tingkat loyalitas dengan mediasi kepercayaan pasien, epercayaan pasien menjadi variabel penting dalam mendapatkan loyalitas pasien baik kepercayaan pasien terhadap sistem kesehatan maupun terhadap tenaga kesehatan. Robinson (2016) menjelaskan terbentuknya loyalitas pasien penyakit kronis dan keluarganya dalam proses pengobatannya. Penelitian ini menjelaskan proses yang dilalui oleh pasien dan yang harus dilewati oleh pemberi pelayanan, dikarenakan pengobatan penyakit kronis mengambil waktu yang lama, loyalitas pasien dan kepercayaan kepada tenaga kesehatan menjadi sangat penting untuk menyokong kualitas hidup yang baik bagi pasien. Proses tersebut terbagi menjadi tiga tahap, proses pertama adalah kepercayaan naif, kepercayaan pasien dimulai dari kepercayaan naif yaitu kepercayaan yang pasrah dan beranggapan bahwa tenaga kesehatan akan membantu mereka agar mencapai kesembuhan. Sayangnya dalam penyakit kronis hal ini tak akan berlangsung secara permanen sehingga saat terjadi kekambuhan, akan muncul kerusakan terhadap kepercayaan.

Kepercayaan yang rusak kemudian akan berlanjut pada kekecewaan karena penyelesaian dirasa hanya bersifat jangka pendek, pada tahap ini pasien dan keluarga kemudian mulai sadar bahwa penyakit kronis itu membutuhkan waktu yang lama dan perawatan berkelanjutan. Setelah menyadari pentingnya kontiunuitas pelayanan, pasien kemudian akan melakukan jalinan kerjasama dengan pemberi pelayanan yang dianggap dipercaya, diperlukan relasi dengan tipe team playing yaitu relasi yang memiliki sifat kepercayaan tinggi terhadap pemberi pelayanan dan kepercayaan tinggi keluarga dan pasien bahwa mereka mampu mengontrol penyakitnya, dengan mencapai hubungan dengan tipe team playing, keluarga dan pasien mampu memiliki kepuasan karena bisa hidup dengan baik dan memiliki loyalitas kepada tenaga kesehatan.
4. Inovasi Pelayanan dalam Peningkatan Kepuasan dan Loyalitas Pasien

Model pelayanan dalam meningkatkan kualitas untuk meraih kepuasan dan loyalitas pasien diperlukan model yang baik dan sesuai dengan kebutuhan serta keinginan pasien. Pengembangan model pelayanan ini dibahas dalam penelitian Klemes dan Solomon (2015), pengembangan pelayanan dilaksanakan dengan memberikan pelayanan preventif penyakit terpersonalisasi untuk pasien, inovasi ini dinamakan dengan MDVIP (Medical Doctor Value-in-Prevention). Inovasi MDVIP dalam mereformasi pelayanan kesehatan primer dengan model pelayanan yang menitikberatkan pada pemberdayaan pasien, pelayanan diberikan atas dasar preventif kejadian penyakit dimasa depan secara individual hingga program terkait perubahan gaya hidup. Hubungan pasien dengan dokter menghasilkan 97\% hubungan yang memuaskan karena pasien menilai lebih banyak hal yang bisa mereka ungkapkan dibandingkan dengan model pelayanan reguler $72 \%$ pasien MDVIP memiliki loyalitas ditandai dengan keinginan mereka untuk tidak meninggalkan dokter mereka.

\section{SIMPULAN DAN SARAN}

\section{A. Simpulan}

Faktor yang mempengaruhi kepuasan dan loyalitas adalah longitudinalitas pelayanan, kesan pertama pasien dan sifat familycentered dalam pelaksanaan pelayanan, Loyalitas didasarkan atas kepuasan dan kepercayaan pasien terhadap pemberi pelayanan kesehatan yang terbentuk perlahan. Hubungan relasional dokter-pasien juga menjadi faktor yang meningkatkan kepuasan hingga berujung pada loyalitas. Pemenuhan kebutuhan sosial juga menjadi faktor yang penting agar pasien memiliki kepuasan yang lebih baik. Kepercayaan menjadi faktor yang menengahi terbentuknya loyalitas setelah muncul kepuasan pasien, terbentuknya loyalitas pasien kepada pemberi pelayanan kesehatan melalui proses munculnya kepercayaan pasien hingga timbul loyalitas. Pemberi pelayanan diharapkan dapat menjadi rekan tim pasien dalam mencapai kesembuhannya. Pelayanan terpersonalisasi dengan pendekatan preventif menjadi inovasi bentuk pelayanan yang dapat meningkatkan kepuasan pasien dan loyalitas kepada dokter 


\section{B. Saran}

Fasilitas kesehatan primer di Indonesia dapat mengadopsi inovasi-inovasi yang ada dengan memperhatikan faktor-faktor terkait kepuasan dan loyalitas, dengan meningkatnya kepuasan dan loyalitas, diharapkan utilisasi pelayanan kesehatan primer dapat tinggi sehingga cakupan pelayanan kesehatan di Indonesia lebih baik.

\section{DAFTAR RUJUKAN}

Eriksson, U. and Svedlund, M. (2007) 'Struggling for confirmation - patients' experiences of dissatisfaction with hospital care', Journal of Clinical Nursing, 16(3), pp. 438-446. doi: 10.1111/J.1365-2702.2005.01544.X.

Gérard, L. et al. (2016) 'The patient, the doctor, and the patient's loyalty: a qualitative study in French general practice', British Journal of General Practice, 66(652), pp. e810-e818. doi: 10.3399/bjgp16X687541.

Gonzalez, A. I. et al. (2020) 'Is there a correlation between the patient-doctor relationship questionnaire and other patient-reported experience measures?', Patient Experience Journal, 7(1), pp. 44-50. doi: 10.35680/2372-0247.1399.

Gray, M., Jones, K. G. and Wright, B. J. (2021) 'Patients With Health-Related Social Needs More Likely to Report Poor Clinic Experiences', Journal of Patient Experience, 8, p. 237437352110083. doi: 10.1177/ 23743735211008307.

Green, B. N., Johnson, C. D. and Adams, A. (2006) 'Writing narrative literature reviews for peer-reviewed journals: secrets of the trade', Journal of Chiropractic Medicine, 5(3), pp. 101-117. doi: 10.1016/S08993467(07)60142-6.

Kijima, T. et al. (2021) 'Patient satisfaction and loyalty in Japanese primary care: a crosssectional study', BMC Health Services Research, 21(1), p. 274. doi: 10.1186/ s12913-021-06276-9.

Klemes, A. and Solomon, H. (2015) 'The Impact of a Personalized Preventive Care Model vs. the Conventional Healthcare Model on Patient Satisfaction', The Open Public Health Journal, 8(1), pp. 1-9. doi: 10.2174/1874944501508010001.
Kotler, P., Roberto, N. and Lee, N. R. (2003) Social Marketing: Improving the Quality of Life (2nd Edition). 2nd edn, undefined. 2nd edn. California: SAGE.

Liu, S. et al. (2021) 'The Impact of Patient Satisfaction on Patient Loyalty with the Mediating Effect of Patient Trust', INQUIRY: The Journal of Health Care Organization, Provision, and Financing, 58, p.004695802110072. doi: 10.1177/ 00469580211007221.

Nidiry, M. A. J. et al. (2008) 'The Closure of a Medical Practice Forces Older Patients to Make Difficult Decisions: A Qualitative Study of a Natural Experiment', Journal of General Internal Medicine, 23(10), pp. 1576-1580. doi: 10.1007/s11606-0080718-6.

Price, R. A. et al. (2014) 'Examining the role of patient experience surveys in measuring health care quality', Medical Care Research and Review, 71(5), pp. 522-554. doi: $10.1177 / 1077558714541480$.

Robinson, C. A. (2016) 'Trust, Health Care Relationships, and Chronic Illness', Global Qualitative Nursing Research, 3, p. 233339361666482. doi: 10.1177/ 2333393616664823.

Sharew, N. T. et al. (2018) 'Investigating admitted patients' satisfaction with nursing care at Debre Berhan Referral Hospital in Ethiopia: a cross-sectional study', BMJ Open, 8(5), p. e021107. doi: 10.1136/ BMJOPEN-2017-021107.

Toufaily, E., Ricard, L. and Perrien, J. (2013) 'Customer loyalty to a commercial website: Descriptive meta-analysis of the empirical literature and proposal of an integrative model', Journal of Business Research, 66(9), pp. 1436-1447. doi: 10.1016/ J.JBUSRES.2012.05.011. 